risk population of TB infection it is reasonable to use both PPD and Diaskin tests, and repeat them every 6 months on treatment.

Disclosure of Interest: None declared

DOI: 10.1136/annrheumdis-2017-eular.6988

\section{AB0312 US7 SCORING SYSTEMS FOLLOW-UP 48 WEEKS TNF-A ANTAGONISTS PLUS MTX TREATMENT FOR HIGH DISEASE ACTIVITY REFRACTORY RHEUMATOID ARTHRITIS}

D.F. Lin ${ }^{1}$, X. Gu ${ }^{1}$, J. Cao ${ }^{1}$, Y. Pan ${ }^{2}$, J. Gu ${ }^{1} .{ }^{1}$ Rheumatology department; ${ }^{2}$ Ultrasound department, the 3rd Affiliated Hospital of Sun Yat-Sen University, Guangzhou, China

Background: US7 score is the ultrasound scoring system for rheumatic arthritis (RA) with the most clinical evidence so far. Several reports accessed its interintra-observer agreement, its specificity, sensitivity and practical possibility compared to more complex scoring systems such as 72 -joints scoring systems, which showed it is an convenient tool for clinical use.

Objectives: Our goal is to employ US7 to investigate the ultrasonic changes during biological agents plus MTX Treatment in high disease activity refractory RA patients in Yellow people.

Methods: All cases were diagnosed as RA fulfilling 2009 ACR/EULAR classification criteria and evaluated as high disease activity for DAS28>5.1 with MTX+HCQ+SASP or MTX+LEF invalid therapy for more than 3 months before baseline. Biological agents including TNF-a antagonist or IL-6 antagonist plus with MTX 10mg qw were then given and ultrasound was performed by 2 observers blinded to physicial examinations and blood tests at 0,4,12, 24, 48w. US examination referred to US7 scores by Backhaus et al. DAS28 were employed to assess disease activity.

Results: 1) 26 subjects were enrolled in the program up to now. 22 were given TNF-a antagonists and 4 were given IL- 6 antagonists. 17 finished 24 weeks follow-up. 1 withdrew for TB infection at 12 week and 1 withdrew for fungi pneumonia at 8 weeks. Mean age of 17 was $44.3 \pm 11.8$ years old, female-male ratio was 15:2, and disease duration was 71 months. All were RF and ACPA postlve. 2) DAS28-CRP, DAS28-ESR had prominent decrease from 0 to 24 week (DAS28CRP: 0w: 4w: 12w: 24w = 6.76, 5.98, 5.09, 4.48, DAS28-ESR: 0w: 4w: 12w: 24w $=6.36,4.94,3.99,3.35$, paired Wilcoxon test, all sig<0.05)

3) The same prominent improvement also well reflected by the ultrasonic scores: average sum scores (0w:4w:12w:24w $=22.9: 15.6: 13: 9.3$, all sig $<0.05$ except $4 w$ : $12 \mathrm{w}, \mathrm{sig}=0.126)$, synovitis grey scale scores $(0 \mathrm{w}: 4 \mathrm{w}: 12 \mathrm{w}: 24 \mathrm{w}=11.6: 9.3: 8.1: 6.0$, all sig $<0.05$, except $0 w: 4 w$, sig $=0.068$ ), synovitis Power Doppler scores (0w:4w:12w:24w = 8.5:4.9:3.8:2.7, all sig <0.05, except 4w:12w,4w:24w, 12w:24w, sig $=0.361,0.227,0.235)$, tenosynovitis grey scale scores $(0 \mathrm{w}: 4 \mathrm{w}: 12 \mathrm{w}: 24 \mathrm{w}=$ 0.63:0.25:0.25:0.07, all sig $<0.05$, except $4 \mathrm{w}: 12 \mathrm{w}, 4 \mathrm{w}: 24 \mathrm{w}, 12 \mathrm{w}: 24 \mathrm{w}, \mathrm{sig}=1.0$, $0.26,0.26)$, tenosynovitis Power Doppler scores (0w:4w:12w:24w $=1.00: 0.19: 0: 0$ all sig $<0.05$, except $4 w: 12 w, 4 w: 24 w, 12 w: 24 w$, sig $=0.18,0.18,1.0$ ), bone erosion scores (0w:4w:12w:24w $=1.2: 1.0: 0.94: 0.53$, all sig $<0.05$ except $0 w: 4 w$, $4 w: 12 w, 4 w: 24 w, 12 w: 24 w, s i g=0.083,0.317,0.102,0.102)$. The above data showed the sum scores found biological agents improved thorough the whole course as Das28 did. Synovitis seemed to be eliminiated faster than tenosynovitis and the repair of bone erosion was the latest event compared to decreased synovitis and tenosynovitis.

Conclusions: It is recommended US7 used in clinic for US7 scoring system could reflect more exquisitely than DAS28 in more refined aspects including the changes of tendon, joint, bone at different phrases during biological agent treatment for RA. However, more samples should be included in our study to illuminate above conclusion with sufficient evidence.

Disclosure of Interest: None declared

DOI: 10.1136/annrheumdis-2017-eular.2640

\section{AB0313 CARDIOVASCULAR RISK, BIOLOGICS AND ANTI-CYCLIC CITRULLINATED PEPTIDE POSITIVITY IN RHEUMATOID ARTHRITIS}

E.A. Jauregui, C.A. Agudelo, C. Aldana, Y.A. Muñoz. Rheumatology, Riesgo de fractura S.A-CAYRE, Bogotá, Colombia

Background: Co-factors and traditional cardiovascular disease (CVD) risk factors contribute to atherosclerosis in rheumatoid arthritis (RA). Several records since 1953 have reported an increase of up to 4 times the CVD risk and mortality in RA patients. Physicians who evaluate these patients forget to perform or record this assessments in medical records. Since 1948, the Framingham Heart Study became an ambitious project in health research, to identify the general causes of heart disease and stroke, they proposed a new risk estimator of general cardiovascular risk defined as CVD.This estimator was calibrated for Colombia and should be multiplied by a factor of 0.7

Objectives: To describe whether the request and registration of $\mathrm{CV}$ risk factors is performed. Also to estimate 10-year risk of CVD in RA patients and to compare the CVD risk among patients receiving or not biological therapy and those with positive and negative anti-cyclic citrullinated peptide (anti-CCP)

Methods: We conducted an observational descriptive study of patients who attended a specialized rheumatology clinic in Bogotá, Colombia from 2010 to 2015. Patients with RA were enrolled who had completed at least 5 year of follow-up. The information required to estimate CVD risk was obtained from medical records. Other variables included were biological therapy and test result of anti-CCP. For the calculation of CVD risk, the Framingham estimator was used and adjusted for the Colombian population. Additionally, patients who had 2 or more of these criteria: More than 10 years of evolution of RA, positive rheumatoid factor and/or extra-articular compromise, the risk was adjusted by multiplying by 1.5. Nonparametric statistics (Mann-Whitney U test) was used.

Results: We identified 273 eligible patients with RA with mean age $61,66 \%$ women. Only $117(42.8 \%)$ had recorded in their charts all variables to calculate CVD risk. We found that $32 \%$ had high blood pressure, $7 \%$ type II DM, $11 \%$ Obesity and $13 \%$ smoking. For the population evaluated, 10 -year CVD risk median was $12.42 \%$ and for Colombia was $8.69 \%$, adjusting this risk according to the disease in Colombia, increased to $13.03 \%$. When we compare the 10-year CVD risk in anti-CCP positive patients (median: 11.15) and anti-CCP negative (median: 8.22) we did not find difference (p: 0.614). However, we found differences in the 10-year CVD risk median 9.04 vs. $23.25,10$-year CVD risk adjusted to Colombia median 6.32 vs. 16.31 and 10-year CVD risk adjusted to Colombia and RA median 6.81 vs. 13.39 between patients using biological therapy versus patients without receiving respectively $(\mathrm{p}:<0.001)$

Conclusions: Only $42.8 \%$ of the sample had all CV risk factors requested and registered in the clinical record, so should promote improvement in the health team to increase this. The average 10-year CVD risk in all people with RA was $12.42 \%$, and in patients who met the criteria to be multiplied by the factor 1.5 increased to $13.03 \%$, which means that these patients should be reported this and applied risk prevention guidelines regarding obesity and cholesterol levels. Despite population receiving biologics are younger, they had lower CV risk. We need more research to confirm this results

References:

[1] Goff DC Jr, et al. 2013 ACC/AHA Cardiovascular Risk Guideline.

[2] M J L Peters, D P M Symmons, D McCarey et al. Ann Rheum Dis 2010;69:325-331.

[3] Arnett D, Goodman R, Halperin J, et al. Circulation. 2014; 130: 1662-1667.

Disclosure of Interest: None declared

DOI: 10.1136/annrheumdis-2017-eular.6465

\section{AB0314 HIGH INFLAMMATORY ACTIVITY AS A PREDICTOR OF INCREASED ARTERIAL STIFFNESS IN PATIENTS WITH RHEUMATOID ARTHRITIS}

E. Troitskaya, S. Velmakin, S. Villevalde, Z. Kobalava. Propaedeutics of internal disease, RUDN University, Moscow, Russian Federation

Background: Patients with rheumatoid arthritis (RA) have a high risk of cardiovascular (CV) morbidity and mortality. Arterial stiffness (AS) is a known predictor of CVD. Relationships between inflammation and arterial stiffness in patients with RA are not well understood.

Objectives: The aim of the study was to evaluate parameters of (AS) and their associations with inflammatory activity in patients with RA.

Methods: 62 patients with RA (EULAR 2010) without known CVD were examined (73\% females,age $58,5 \pm 15,4(\mathrm{M} \pm \mathrm{SD}$ ) years, $13 \%$ smokers, $61 \%$ with $\mathrm{AH}, 34 \%$ with dyslipidemia). Median duration of RA was 8 years (IQR 3-17). Seropositive RA was diagnosed in $69 \%$ of patients. Median hsCRP was $12,1 \mathrm{mg} / \mathrm{dl}$ (IQR 2,2;23,4 $\mathrm{mg} / \mathrm{dl}$ ), median rheumatoid factor (RF) was $32,5 \mathrm{IU} / \mathrm{ml}$ (IQR 8,3;173 IU/ml). Mean DAS-28 (ESR) was $4,7 \pm 1,2$. All patients received disease-modifying antirheumatic drugs, $22(38 \%)$ - biological treatment. Parameters of AS were assessed by applanation tonometry (SphygmoCor, AtCor). Cardio-ankle vascular index (CAVI), ankle-brachial index (ABI) and vascular age were measured by VaSera 1500. Carotid intima-media thickness (CIMT) was evaluated by ultrasound. Pulse wave velocity $>10,0 \mathrm{~m} / \mathrm{s}$ and $\mathrm{CAVI}>9,0$ were considered as $\mathrm{AS}$ increase. $\mathrm{ABI}<0,9$ and CIMT $>0,9$ were considered as markers of subclinical atherosclerosis. $p<0.05$ was significant.

Results: Mean PWV was $9,3 \pm 3,2 \mathrm{~m} / \mathrm{s}$. PWV $>10 \mathrm{~m} / \mathrm{s}$ was observed in $32,3 \%$ patients, $\mathrm{CAVI}>9,0$ - in $25,8 \%, \mathrm{ABI}<0,9-$ in $6,5 \%$ and $\mathrm{CIMT}>0,9-$ in $21 \%$. Patients with $P W V>10 \mathrm{~m} / \mathrm{s}$ were older $(69,8 \pm 8,5$ vs $53,2 \pm 15,1$ years), had higher $\operatorname{BMI}\left(29,3 \pm 6,5 \mathrm{vs} 24,7 \pm 4,8 \mathrm{~kg} / \mathrm{m}^{2}\right.$ ), longer duration of $\mathrm{AH}$ (median 11,5 [IQR 5,$5 ; 17$ ] vs 0 [IQR $0 ; 5]$ years), higher BP levels $(144 \pm 20 / 85 \pm 9$ vs $123 \pm 14 / 77 \pm 10 \mathrm{mmHg}$ ), lower level of GFR $\left(64 \pm 17\right.$ vs $\left.89 \pm 19 \mathrm{ml} / \mathrm{min} / 1,73 \mathrm{~m}^{2}\right)$, higher levels of LDL-C $(3,7 \pm 0,9$ vs $3,2 \pm 1,0 \mathrm{mmol} / \mathrm{l})$, plasma glucose $(5,6 \pm 0,9 \mathrm{vs} 4,8 \pm 0,7 \mathrm{mmol} / \mathrm{l})$, hs-CRP (median 22 [IQR 13,3;60] vs 6,7 [IQR 1,6;17,2] mg/dl), higher CAVI $(9,5 \pm 1,1$ vs $7,6 \pm 1,4)$, vascular age $(71 \pm 8,4$ vs $53,4 \pm 17,5$ years) and CIMT $(1,01 \pm 0,3$ vs $0,7 \pm 0,2 \mathrm{~mm}), p<0,05$ for trend. Spearmen analysis revealed significant positive correlations between PWV and age $(r=0,7)$, BMI $(r=0,4)$, duration of $\mathrm{AH}(\mathrm{r}=0,6)$, $\operatorname{SBP}(r=0,6)$, DBP $(r=0,4)$, plasma glucose $(r=0,3)$, hs-CRP $(r=0,3)$, vascular age $(r=0,6)$, CIMT $(r=0,7)$, CAVI $(r=0,6)$ and negative correlations with eGFR $(r=-0,6)$. hsCRP correlated with PWV, aortic pulse pressure $(r=0,3), C A V I(r=0,5)$, vascular age $(r=0,5)$ and $A B I(r=-0,5)$. Multiple regression analysis confirmed that $A H$ duration $(\beta=0,2, p=0.03)$, SBP $(\beta=0,6, p<0.0001)$, GFR $(\beta=-0,3, p=0,005)$ and hs-CRP-level $(\beta=0,3, p=0.000009)$ were independent predictors of AS increase. Conclusions: High prevalence of AS increase is observed in patients with RA without known CVD. Elevation of hsCRP as well as other traditional risk factors is an independent predictor of PWV increase in patients with RA.

References:

[1] Ambrosino P. et al. Subclinical atherosclerosis in patients with rheumatoid 
arthritis. a meta-analysis of literature studies. Thromb Haemost 2015;113:916930

[2] Crilly M. et al. Arterial stiffness and cumulative inflammatory burden in rheumatoid arthritis:a dose-response relationship independent of established cardiovascular risk factors Rheumatology 2009;48:1606-1612.

[3] Silem H., Nasr G. Change of the aortic elasticity in rheumatoid arthritis: Relationship to associated cardiovascular risk factors $\mathrm{J}$ Cardiovasc Dis Res. 2010;1:110-115.

Disclosure of Interest: None declared

DOI: 10.1136/annrheumdis-2017-eular.6495

\section{AB0315 THE POTENTIAL ASSOCIATION BETWEEN RHEUMATOID ARTHRITIS AND TRADITIONAL CARDIOVASCULAR RISK FACTORS: A META-ANALYSIS OF CONTROLLED STUDIES}

E. Filhol $^{1}$, C. Gaujoux-Viala ${ }^{2}$, B. Combe ${ }^{1}$, J. Morel $^{1}$, C. Hua ${ }^{1}$, A. Nutz ${ }^{2}$, C. Lukas ${ }^{1}$, F. Flaisler ${ }^{2} .{ }^{1}$ Lapeyronie Hospital, Montpellier; ${ }^{2}$ Nimes Hospital, Nimes, France

Background: Systemic inflammation is the cornerstone of both rheumatoid arthritis (RA) and atherosclerosis. RA is currently considered as a cardiovascular risk factor.

Objectives: The aim of this systematic review was to assess the association between RA and the traditional cardiovascular risk factors (hypertension, dyslipidemia, diabete mellitus, and atherosclerosis) in RA patients in comparison to the general population.

Methods: We systematically searched literature (via Pubmed, Cochrane and abstracts from recent ACR and EULAR congresses) up to March 2016 for observational studies providing data concerning the presence of a traditional cardiovascular risk factor (among hypertension, dyslipidemia, diabetes mellitus, atherosclerosis) in patients with RA and in a control group. A meta-analysis of the relative risk $(R R)$ concerning patients with $R A$ in relation to the control group was performed for each cardiovascular risk factor.

Results: Out of 5714 screened references, 13 studies were included. Due to lack of data, atherosclerosis studies could not be included in this meta-analysis. For hypertension and diabetes, an increased risk was observed: $R R=1.15$ [95\% Cl 1.07-1.24], $p=0.0003$ and $R R=1.11$ [1.04-1.19], $p=0.001$, respectively. On the contrary, not any association was found with the dyslipidemia ( $R R=0.93$ [0.77-1.12], $p=0.43$ ).

Conclusions: This meta-analysis highlights a moderate excess risk of hypertension and diabetes among patients with RA relative to the general population. A comprehensive identification of cardiovascular risk profile of RA is an opportunity to improve health management of these patients. Future research is crucial in order to establish to what extent the control of modifiable risk factors can improve cardiovascular outcome of these patients.

Disclosure of Interest: None declared

DOI: 10.1136/annrheumdis-2017-eular.5432

\section{AB0316 HOSPITAL ADMISSIONS OF PATIENTS WITH RHEUMATOID ARTHRITIS TREATED WITH DMARD}

E.C. Cervantes Pérez, J.R. Maneiro, A. Souto Vilas, J.A. Mera Varela, J.J. Gómez-Reino. Ramón Domínguez Foundation, University Hospital Complex of Santiago de Compostela, Santiago de Compostela, Spain

Objectives: To describe hospital admissions and contributing factors in patients with rheumatoid arthritis (RA) treated biological DMARD (b-DMAR) and conventional synthetic DMARD (cs-DMAR).

Methods: Retrospective observational study of RA patients admitted to the hospital for any cause from 2010 to 2015. Demographic, clinical and therapeutic characteristics were collected from the medical charts. Multivariate and univariate models were used to identify variables associated with admissions for any cause, major adverse cardiovascular events (MACE), and infection. The statistical program Stata 14.0 was used for the analysis.

Results: In the period $2010-2015,26 \%$ of all RA patients were treated with b-DMARD. There were a total of 1251 hospital admissions for any cause in 600 patients; 1055 admissions in 477 patients treated with cs-DMAR and 196 admissions in 123 patients treated with b-DMAR. Of the 1251 admissions, 251 were due to infections and 60 to MACE. Demographic characteristics,

Table, Demographic characteristics, comorbidities and treatment in 600 patients admitted to an university hospital.

\begin{tabular}{|l|c|c|c|c|}
\hline & $\begin{array}{l}\text { AR patients } \\
\text { admitted (600) }\end{array}$ & $\begin{array}{c}\text { Patients b-DMAR } \\
\text { treated (123) }\end{array}$ & $\begin{array}{c}\text { Patients cs-DMAR } \\
\text { treated (477) }\end{array}$ & $\mathrm{p}^{*}$ \\
\hline $\begin{array}{l}\text { Age }>65 \\
\text { years }\end{array}$ & 428 & $59(47.97 \%)$ & $369(77.36 \%)$ & 0.03 \\
\hline Female & 412 & $88(71.54 \%)$ & $324(67.93 \%)$ & 0.269 \\
\hline COPD & 59 & $8(6.96 \%)$ & $51(10.81 \%)$ & 0.062 \\
\hline $\begin{array}{l}\text { Diabetes } \\
\text { mellitus }\end{array}$ & 109 & $10(8.70 \%)$ & $99(20.97 \%)$ & 0.364 \\
\hline Dyslipemia & 161 & $23(20.00 \%)$ & $138(29.30 \%)$ & 0.025 \\
\hline $\begin{array}{l}\text { Arterial } \\
\text { hypertension }\end{array}$ & 295 & $41(35.65 \%)$ & $254(53.93 \%)$ & $<0.001$ \\
\hline $\begin{array}{l}\text { Corticoids } \\
\text { 'Chronic obstructive pulmonary disease, }\end{array}$ & $490.32 \%)$ & $403(85.74 \%)$ & 0.162 \\
\hline
\end{tabular}

comorbidities and treatment are disclosed in table. In the multivariate analysis, diabetes mellitus $(p<0.001)$, and hypertension $(p=0.029)$ were associated with admission for infections, and hypertension ( $p$ 0.011), and dyslipidemia $(p=0.02)$ with admissions for MACE.

Conclusions: infections and MACE are a significant cause of hospital admission in patients with rheumatoid arthritis. Comorbidities as diabetes, hypertension and dyslipidemia but not b-DMARD are significantly associated with admission for infection or MACE.

Disclosure of Interest: None declared

DOI: 10.1136/annrheumdis-2017-eular.6769

\section{AB0317 RHEUMATIC DISEASES AND PREGNANCY: PRACTICE PATTERNS AMONG RHEUMATOLOGISTS AND OBSTETRICIANS IN LEBANON}

F. Fayad ${ }^{1,2}$, N. Ziade ${ }^{1,2}$, G. Abi Karam ${ }^{1,2}$, W. Ghaname ${ }^{3,4} .{ }^{1}$ Saint Joseph University; ${ }^{2}$ Hotel Dieu de France University Hospital, Beirut; ${ }^{3}$ Holy Spirit University, Kaslik; ${ }^{4}$ Notre Dame de Secours University Hospital, Jbeil, Lebanon

Background: For years, women with potentially serious systemic diseases, such as rheumatic diseases (RD), have been advised against getting pregnant. However, with careful clinical management, most of these women can have successful pregnancies. The use of RD drugs before or during pregnancy is problematic due to the lack of knowledge about their compatibility with pregnancy. Recently, the British Society of Rheumatology (BSR) and the European League Against Rheumatism (EULAR) published guidelines on prescribing drugs in pregnancy and breastfeeding.

Objectives: To evaluate the perceptions and clinical practices of rheumatologists and obstetricians in Lebanon regarding the use of medications prior and during pregnancy and breastfeeding. The secondary objective was to assess the variables that are significantly associated with the physicians' adherence to guidelines.

Methods: A national, observational, cross-sectional physician survey was conducted among a representative sample of rheumatologists and obstetricians throughout Lebanon. Collected data included physicians' information (age, gen-

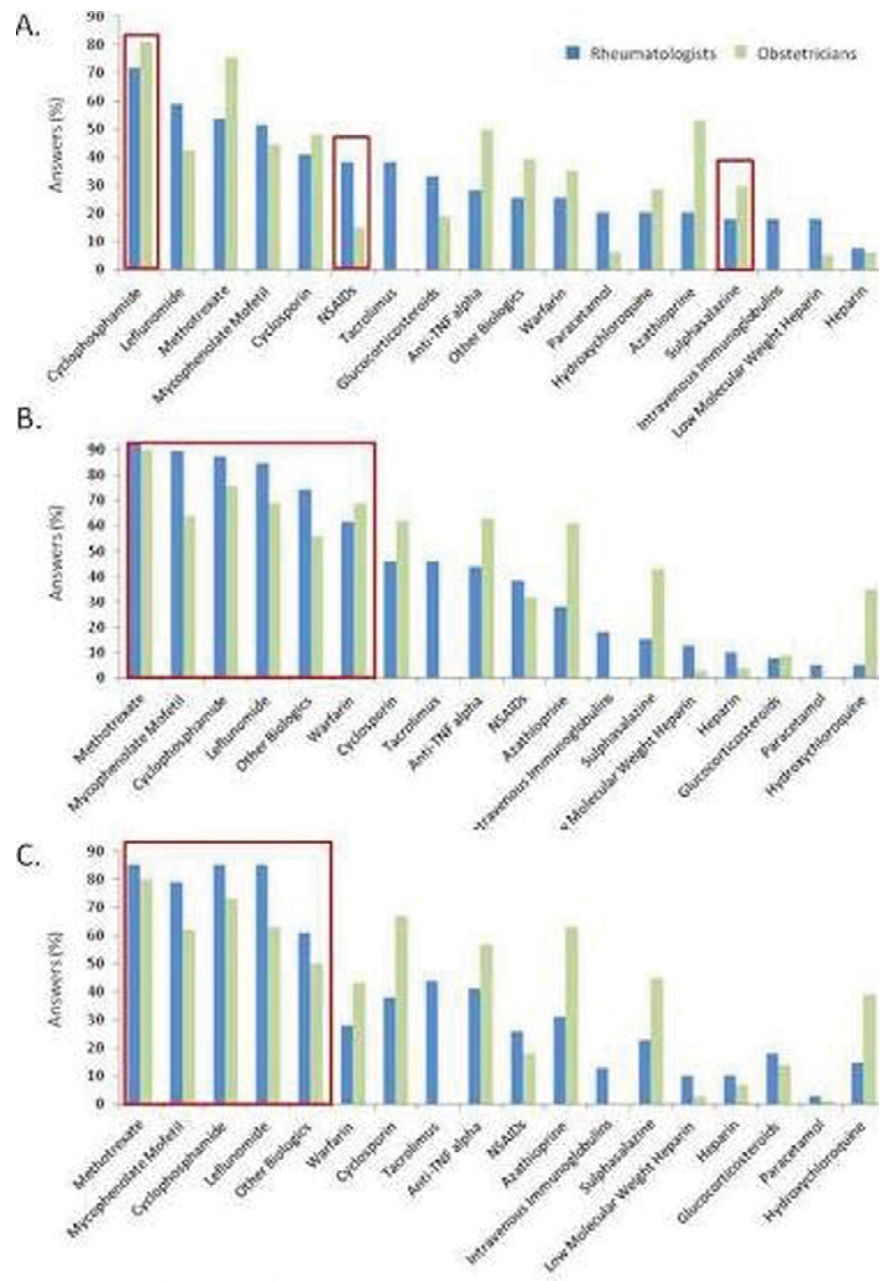

Figure 1. Percentage of rheumatologists and obstetricians who consider RD medications detrimental to fertility $(A)$, pregnancy $\{B\rangle$ and breastfeeding $\langle C\rangle$. Red squares indicate answers in accordance with EULAR/BSR guidelines. 